\title{
Acoustic and visual courtship traits in two sympatric marine Gobiidae species - Pomatoschistus microps and Pomatoschistus minutus
}

\author{
Eva-Lotta Blom • Isabel Mück • Katja Heubel • \\ Ola Svensson
}

Received: 4 May 2016 / Accepted: 4 November 2016/Published online: 16 November 2016

(C) The Author(s) 2016. This article is published with open access at Springerlink.com

\begin{abstract}
Divergence in courtship traits across species can evolve as adaptations to different environments, and also through avoidance of reproductive interference and character displacement. Differences may also be explained by phylogenetic relationships. We compared different courtship traits, including male courtship sounds, in two sympatric Pomatoschistus species. Both species are characterised by having male and female courtship, and paternal care of eggs in nests under mussel shells and rocks. In addition to presenting novel observations, we reviewed the literature on courtship traits for both species and complemented it with new observations. We found that courting males of the common goby $P$. microps sing louder and produce sounds of shorter duration than males of the sand goby P. minutus.
\end{abstract}

Eva-Lotta Blom and Isabel Mück contributed equally to this work. Katja Heubel and Ola Svensson contributed equally to this work.

E.-L. Blom • O. Svensson $(\bowtie)$

Department of Biological and Environmental Sciences, University of Gothenburg, Box 463, SE-405 30 Gothenburg, Sweden e-mail: ola.svensson@bioenv.gu.se

I. Mück

Animal Evolutionary Ecology, University of Tübingen, Auf der Morgenstelle 28, D-72076 Tübingen, Germany

K. Heubel

Institute for Zoology, Research Station Grietherbusch, University of Cologne, D-50923 Cologne, Germany

O. Svensson

The Linnaeus Centre for Marine Evolutionary Biology, University of Gothenburg, Gothenburg, Sweden
Furthermore, males of $P$. microps swim faster towards females during courtship than males of $P$. minutus. The eyes of $P$. minutus females turn black during courtship attempts, whereas this is not the case for females of P. microps. Species-specific differences in courtship sounds and behavior may lead to different susceptibility of the two species to environmental change such as noise pollution and turbidity.

Keywords Acoustic communication - Character displacement - Gobiidae · Mate choice - Sexual selection . Sound signal production

\section{Introduction}

Animals use a wide range of modalities during courtship and the effectiveness of signals co-varies with environmental conditions (Bradbury and Vehrencamp 2011; Candolin and Wong 2012). Therefore, signals (including acoustic signals) often match measures of optimal signal transmission (Bradbury and Vehrencamp 2011; Wilkins et al. 2013). Under turbid conditions, visual courtship signals can be hampered (Järvenpää and Lindström 2004; Seehausen et al. 1997; Heubel and Schlupp 2006) and changes in pH-levels can modify the use of chemical cues (Heuschele and Candolin 2007). Recently, acoustic communication and its interaction with environmental properties and background noise have been of particular interest (Radford et al. 2014; Holt and Johnston 2015). In the so called 'sand goby group' (family Gobiidae, Huyse et al. 2004), at 
least eight species have been shown to produce low frequency acoustic pulses in a reproductive context (Malavasi et al. 2012; Bolgan et al. 2013; Pedroso et al. 2013; de Jong et al. 2016) two-spotted goby Gobiusculus flavescens (Fabricius, 1779), Adriatic dwarf goby Knipowitschia panizzae (Verga, 1841), Italian spring goby Knipowitschia punctatissima (Canestrini, 1864) canestrini's goby Pomatoschistus canestrini (Ninni, 1883), marbled goby Pomatoschistus marmoratus (Risso, 1810), common goby Pomatoschistus microps (Krøyer, 1838) (one individual only), sand goby Pomatoschistus minutus (Pallas, 1770) and painted gobyPomatoschistus pictus (Malm, 1865). The functions of these sounds are still unknown, but they have been proposed to be used in male courtship and female choice (Lugli and Torricelli 1999; Lindström and Lugli 2000; Pedroso et al. 2013), or in species recognition (Pedroso et al. 2013).

$P$. minutus and P. microps are small marine fish distributed in lagoons, coastal areas and estuaries of the Atlantic, Mediterranean and Baltic region (Miller 1986; Kullander et al. 2012). The two species are sympatric in the study area on the west coast of Sweden, with an extensive overlap between their habitats. However, $P$. microps is more abundant in very shallow and often muddy areas, whereas $P$. minutus is usually found on sandy bottoms and in slightly deeper $(>0.5 \mathrm{~m})$ water (personal observation, Miller 1986; Nellbring 1986; Nellbring 1993; Kullander et al. 2012). During a single breeding season, these short-lived fishes (12 years) can reproduce repeatedly with different mates (Miller 1975; Miller 1986; Kullander et al. 2012). There is an overlap in the breeding season between species, with spawning peaks occurring in spring and early summer (earlier peak in P. minutus, range March to July, and later peak in P. microps, May to September Kullander et al. 2012). Males of both species generally establish territories and build a nest by covering mussel shells with sand. Both species attract females with visual courtship displays and males provide exclusive paternal care until the eggs hatch (Forsgren 1999; Magnhagen 1999). P. minutus males prepare the surface of the nest ceiling with sperm-containing mucus on which the eggs are laid (Svensson and Kvarnemo 2005). This is most likely also the case for P. microps (Svensson et al. 1998). It has been shown in other gobies that the mucus contains pheromones (Locatello et al. 2002), and has antimicrobial functions (Giacomello et al. 2008). This antimicrobial function can also be important in female choice because egg infections have an effect on egg survival (Lehtonen and Kvarnemo 2015a; Vallon et al. 2016) and influence female choice (Lehtonen and Kvarnemo 2015b). P. minutus and P. microps are highly sympatric and often occur in close proximity, competing over the same nest resources (personal observation). There is a substantial overlap in terms of fish size, depth, and bottom structure and thus interspecific interference is a real concern.

The aim of our paper is to describe and compare the courtship sound and behavior of two highly sympatric goby species. We reviewed the literature on descriptions of previously studied traits and behavior in P. minutus and P. microps and aim to build a foundation and concise, accessible reference for further studies of acoustical and behavioral traits in different species of gobies. Closely related species are expected to avoid reproductive interference (Gröning and Hochkirch 2008) and diverge through character displacement (Pfennig and Pfennig 2009). Therefore, we predict differences in the courtship sounds, and behavioral and morphological courtship traits facilitating discrimination between the two species with extensive habitat overlap.

\section{Methods}

We conducted the experiment at The Sven Lovén Centre of Marine Infrastructure in Kristineberg on the west coast of Sweden $\left(58^{\circ} 15^{\prime} \mathrm{N}, 11^{\circ} 27^{\prime} \mathrm{E}\right)$ during the last 2 weeks in June 2013. All aquaria, including experimental aquaria, had continuously renewed surface seawater (salinity 22-34, temperature $12.8-13.4{ }^{\circ} \mathrm{C}$ ) and a layer of fine sand for the fish to hide in and to use as nest material. Light was provided through large windows and hence followed the natural Swedish summer light regime of $18 \mathrm{~h}$ between sunrise and sunset (it is never completely dark). We blocked visual interactions across all tanks. We caught all fish by hand trawling in bays nearby the station and kept them separated by species and sex in different storage tanks (20-50 1) for 2-14 days before the experiment started. We fed the fish once a day with commercial fish food granules (Nutra HP, Skretting).

\section{Experimental set up}

We placed the experimental aquaria (201) on top of two marble layers interspaced with cones of silicon for 
sound insulation. All males ( $P$. microps $n=10$, $P$. minutus $n=10$ ) had access to an artificial nest, made of a piece of polypropylene tube (Ø $56 \mathrm{~mm})$ with a pipe attached like a chimney (Ø $20 \mathrm{~mm})$. To encourage nest building, we introduced a ripe female in a transparent plastic vial in front of the nest in each aquarium. The vial had small holes on the side and a mesh net over the top to allow for water exchange. We inserted a hydrophone into the chimney of the nest (Song Meter SM2+ platform and hydrophone HTI-96-MIN with pre-amplifier, frequency response $2 \mathrm{~Hz}$ to $30 \mathrm{KHz}$, wildlife acoustic, bioacoustics monitoring systems, Maynard, US; $0 \mathrm{~dB}=$ $1 \mathrm{~V} /$ pa@1 KHz, calibrated hydrophone sensitivity $-165 \mathrm{~dB}$ re $1 \mathrm{~V} / \mu \mathrm{P}$, gain $48 \mathrm{~dB}$, sampling frequency $16 \mathrm{KHz}$ ). In front of the aquarium, we set up a camcorder for video recordings (Canon Legria HF M56, Ōta, Tokyo, Japan). We tested P. minutus (which has an earlier peak in breeding season) during the first week, and P. microps in the following week of the experiment. After $12 \mathrm{~h}$ we released the female from the vial and, due to the naturally differing female-biased operational sex ratios reflected in the catches as well as in previous studies (Kvarnemo 1994; Mück 2016), we added two (P. microps) or one (P. minutus) additional females. We recorded visual and acoustic behavior for $60 \mathrm{~min}$. After the trial, we measured the males to the nearest $0.5 \mathrm{~mm}$ ( $\mathrm{L}_{\mathrm{T}}$ P. microps: $33.7 \pm 2.5 \mathrm{~mm} ; \mathrm{L}_{\mathrm{T}}$ P. minutus: $53.8 \pm$ $3.2 \mathrm{~mm})$.

\section{Acoustic courtship}

An acoustic signal produced by a male contains a number of acoustic pulses. These pulses produce a train, which are then clustered into bursts (Fig. 1). We analyzed the two first trains made by each male, following the protocol of Lindström and Lugli (2000), for (1) number of pulses per train, (2) the total train duration $[\mathrm{ms}]$ ), (3) pulse repetition rate (pulse per second i.e. number of pulses per train divided by train duration [s]) and (4) pulse period (time [ms] between two pulses) with Matlab R2009b (The Mathworks Inc., Natick, Massachusetts, USA). As the sound files for P. microps were clipped, we measured (5) average pulse amplitude $[\mathrm{mV}]$ only for P. minutus.

\section{Visual courtship}

All authors independently examined the films, leading to the synthesis of behaviors presented in the ethogram in Table 2. We quantified and scored behavioral data by watching video clips (without the synchronized sound files) of experimental tanks of both species in random order. Therefore, it was observer-blind in terms of acoustic signaling properties. We collected and analyzed the data on frequency and duration (s) of the behavioral states and events (Table 2) using the event recorder JWatcher 1.0 (D. T. Blumstein et al., University of California, USA \& Macquarie University, Australia). We scored the coloration of females and males by rewatching the films with a special emphasis during malefemale interactions (courtship). We have previously observed that $P$. microps males move faster than $P$. minutus males during courtship. To quantify this, we measured courtship movements parallel to the front of the aquaria (the first movement was analyzed). Six males of each species moved in a way, which was possible to analyze. We annotated time (ms) directly form the video recording and measured distances using ImageJ (Rasband, W.S., ImageJ, U. S. National Institutes of Health, Bethesda, Maryland, USA, http://imagej.nih.gov/ij/, 1997-2016).

\section{Data analysis}

In one aquarium we accidently had two P. microps males. However, the subordinate male was dug down in the back corner except for the very first minutes after the release. Thus, we did not use this replicate for the analysis of visual courtship behavior and only included it in the color and sound analyses. The nest-owning male produced the sound inside the nest accompanied by a female.

Sound characteristics were tested with permutation tests (Permutations tester 1.0 Stat Boss Michael J. Lew 2008). We report the median, the range of the sound variables for the five males per species (based on the averages of the two trains produced by each male), as well as the absolute range of all 10 analyzed sounds per species. We used t-tests to test for differences between species in the proportion of the observation time that males spent on courtship, as well as swim speed. We applied square root arcsine transformations to the proportions and a square root transformation to swim speed data prior to testing to fulfill the assumptions for parametric tests. Untransformed means \pm SDs are given in the text and Table 2. 


\section{Results}

Acoustic courtship

Five out of ten $P$. microps males and five out of ten $P$. minutus males produced sound in a reproductive context. One oscillogram from each species is given in Fig. 1. The males of $P$. microps only produced sound inside the nest when accompanied by a female while the males of $P$. minutus also produced sound in the nest opening when a female was close (Table 2). Four $P$. minutus males produced the trains inside the nest while the females were at the nest entrance, and one male of $P$. minutus produced the two first trains when the female was also inside the nest. The latter two trains fall within the range of all sound parameters of the other eight $P$. minutus trains, and thus there was no qualitative difference between courtship sounds produced when the female was inside the nest compared to when she was outside the nest.

P. minutus had a longer duration of the train than P. microps (Table 1). P. microps produced fewer pulses per train than $P$. minutus, although this was not significant. Both species had a similar pulse repetition rate and pulse period (Table 1). All sound files for P. microps males ( $N=$ five males, two sounds per male) were clipped, whereas no sound files from $P$. minutus were clipped ( $N=$ five males, two sounds per male) $(5 / 5$ vs. $0 / 5$, Fisher exact test, $p=0.0079$ ). In both species, all analyzed sounds were produced when the males were lying with their abdomen towards the bottom of the nest and with the same distance from the hydrophone $(1 \pm$ $0.5 \mathrm{~cm})$. For $P$. minutus males $(N=5)$ we found the amplitude at a range of $1.5-3 \mathrm{mV}$.

Visual courtship

In Table 2 we provide references and synthesize previously reported courtship traits and behaviors in P. microps and P. minutus. Novel descriptions of observations that we have not found previously reported are the lack of black eyes in courting $P$. microps females and that male $P$. microps swim faster than male $P$. minutus during courtship. We were able to confirm the previously reported traits and behaviors included in our ethogram and provide our observed range and median
Fig. 1 a The figure shows a representative sound of five trains clustered into one burst produced by a common goby

Pomatoschistus microps male. Amplitudes are clipped at $1 \mathrm{~V}$. b The figure shows a representative sound of two trains clustered into on burst produced by a sand goby Pomatoschistus minutus male. Both oscillograms were made in Matlab R2009b (The Mathworks Inc., Natick, Massachusetts, USA)

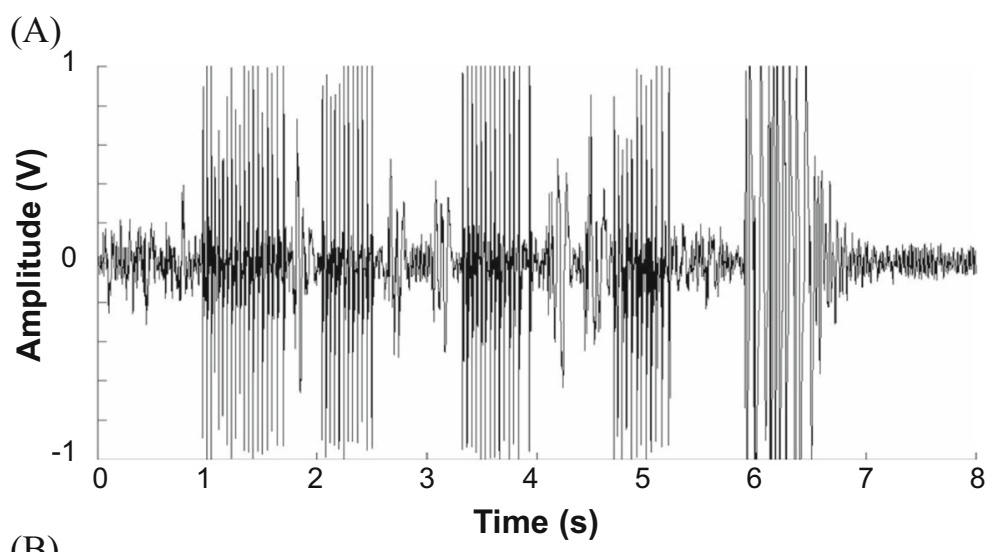

(B)

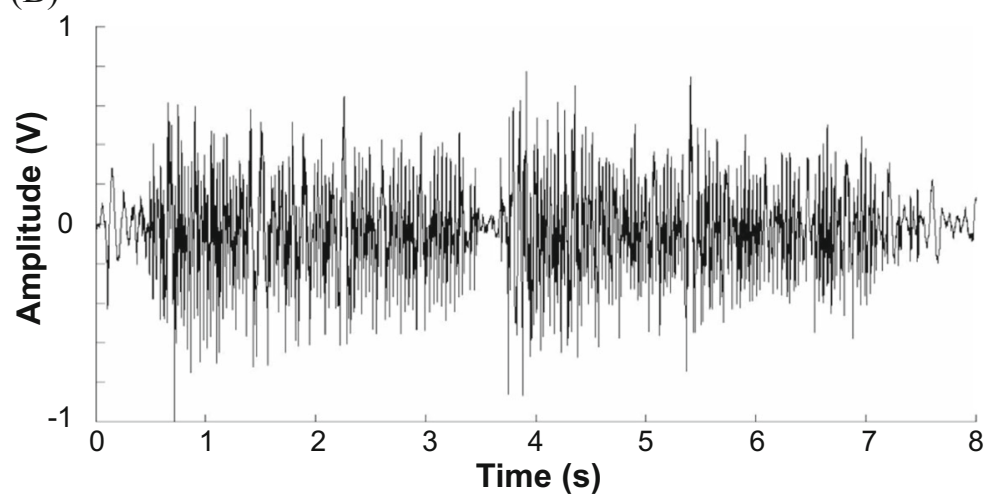


Table 1 Acoustic sound features from males of P. microps and P. minutus produced during courtship

\begin{tabular}{|c|c|c|c|c|c|c|c|}
\hline \multirow[t]{2}{*}{ Acoustic parameters } & \multicolumn{3}{|c|}{ P. microps } & \multicolumn{3}{|c|}{ P. minutus } & \multirow[t]{2}{*}{ Permu-tation test } \\
\hline & Median & Range & Range (abs) & Median & Range & Range (abs) & \\
\hline Number of pulses per train & 15.0 & $11.5-17.5$ & $9.0-18.0$ & 32.5 & $13.0-89.0$ & $10.0-121.0$ & $p=0.055$ \\
\hline Train duration (ms) & 535 & $370-390$ & $280-840$ & 1060 & $625-3450$ & $400-4900$ & $p=0.040$ \\
\hline Pulse repetition rate (pulse/s) & 26.8 & $22.2-37.9$ & $21.4-46.7$ & 26.1 & $20.5-29.5$ & $18.0-31.4$ & $p=0.41$ \\
\hline Pulse period (ms) between two pulses & 39.9 & $38.4-45.1$ & $36.7-46.7$ & 40.0 & $33.3-50.9$ & $30.0-55.0$ & $p=0.95$ \\
\hline
\end{tabular}

Descriptive statistics is based on the median of the two first pulse trains in one burst produced by each male $(P$. microps $n=5$ males, $P$. minutus $n=5$ males). Range is the range of the means of the two analyses sounds from each male ( $n=5$ for each species) and range (abs) is the range of all measured sounds $(n=10$ for each species). Significant differences (at alpha $=0.05)$ are presented in bold

for all behaviors (Table 2). Females of both species courted males. During courtship, the eye, and the area around it, of P. minutus females turns black within seconds (Kvarnemo et al. 1995; Forsgren 1997). This black coloration is absent in P. microps females (Table 2). Females of both species present their bellies during courtship, by hopping up and down in small movements in direct proximity to the male. The two species have a similar male nuptial coloration with a black and blue spot on the anterior dorsal fin, which is strongly colored during a courtship attempt. In particular, P. microps has parallel stripes on the flanks and its facial lines are highly conspicuous during courtship. These facial lines are also present in females and more pronounced in P. microps than in P. minutus. P. microps males lack the blue anal fin typical of $P$. minutus and have a brown-red throat in contrast to a grey-white throat found in P. minutus (Table 2). Male courtship behavior is similar with both species starting courtship using fast approaches towards females with erected fins. P. microps males do small jumps with their mouth opened and their gill covers raised, including incidences of physical contact with the female, that sometimes escalate to aggression. Typically, the males of both species swim back to the nest in a conspicuous manner, considered a lead display ('lead swim'), as females may choose to follow the courting male into his nest. Other characteristic behaviors observed between courtship attempts were nest building by fanning sand upon the nest with the tail and 'displacement fanning' (fanning in the nest in the absence of eggs) (Table 2). We did not observe any 'eight displays' (the male swims rapidly in front of the female in a figure of eight pattern) which have been described to be typical for P. pictus (Amorim and Neves 2007). The two species did not differ significantly in the proportion of time spent courting
(P. microps $0.050 \pm 0.06$, P. minutus $0.022 \pm 0.03 ; \mathrm{t}=$ 1.26 , d.f. $=18, p=0.22$ ). During courtship, the short distance movements of $P$. microps were faster than those of $P$. minutus $(\mathrm{t}=2.76$, d.f. $=10, p=0.02$, Table 2$)$.

\section{Discussion}

Here we report several courtship traits, which are generally similar but do bear a few intriguingly distinct differences between two closely related, morphologically and ecologically similar goby species (Huyse et al. 2004; Kullander et al. 2012). One important courtship trait that differs between $P$. microps and P. minutus males are the sounds produced during female attraction. The courtship sound of $P$. microps males has a shorter duration than the one of $P$. minutus males. While the settings of the $\mathrm{dB}$ gain on the hydrophone worked well for $P$. minutus, all sounds of $P$. microps were clipped. Because all sounds were produced inside the nest with the male at the same distance from the hydrophone, we conclude that the courtship sound of $P$. microps most likely is louder than the sound of P. minutus. Previously, Bolgan et al. (2013) reported sound production in one single individual male of $P$. microps, and were hence limited in their analyses of the $P$. microps breeding vocalization. Although our study also suffers from low sample size and methodological issues, we show that there are clear species differences in sound production. By comparing the two species we also highlight that only females of $P$. minutus display black eyes during courtship. During courtship attempts $P$. microps males swim faster than $P$. minutus males. Furthermore, we confirm several previously but separately reported differences (Table 2). We also report for the first time that 


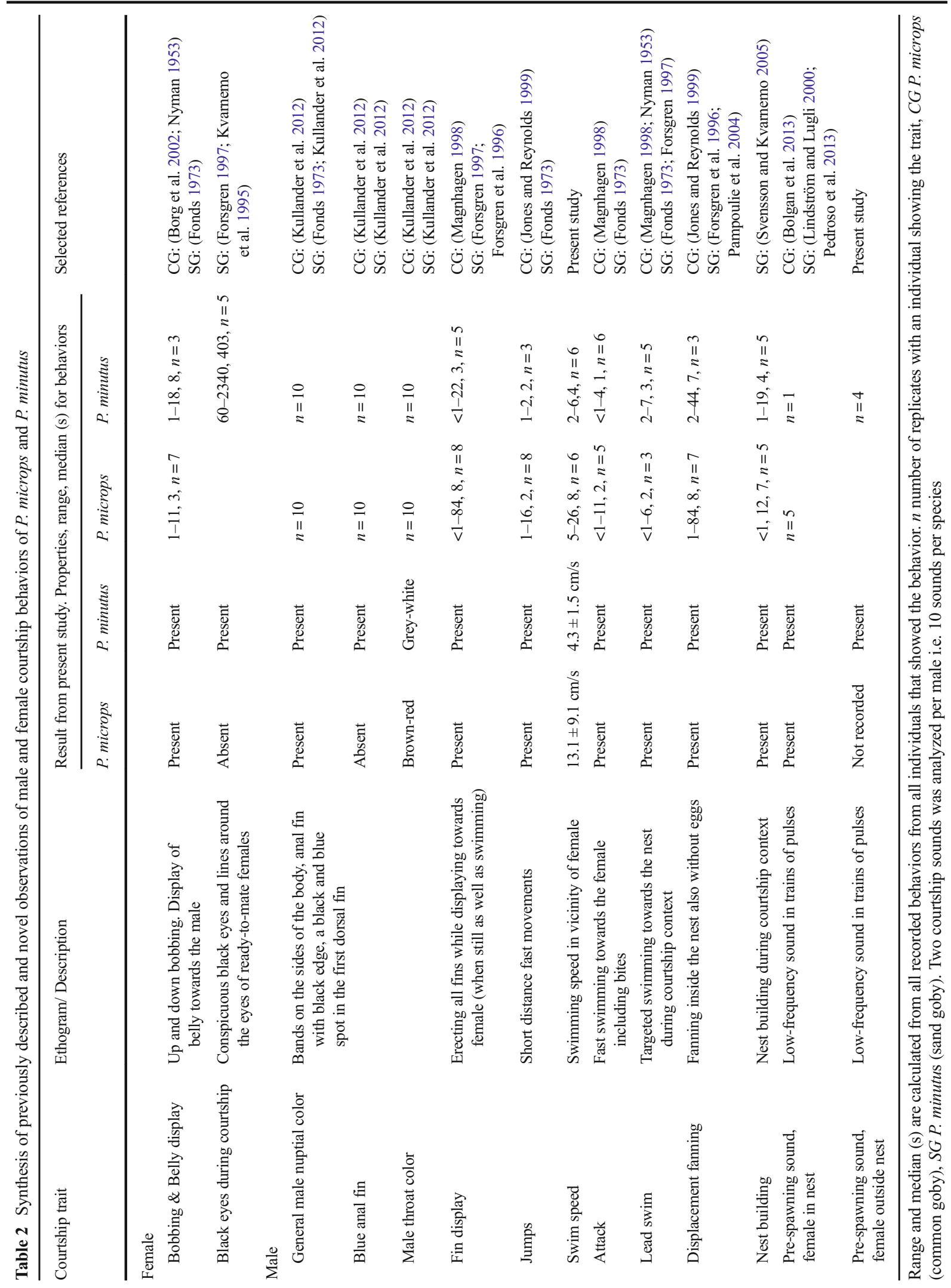


P. minutus produces courtship sounds inside the nest when the female is outside of the nest.

Species differences in courtship sounds, and other traits involved in mate choice, may reflect the phylogenetic history, but they may also have diverged as a response to differences in the physical environment as well as intra- and inter-specific interactions (Gröning and Hochkirch 2008; Pfennig and Pfennig 2009; Bradbury and Vehrencamp 2011; Wilkins et al. 2013). P. microps and P. minutus belong to two different clades of the 'sand goby group' radiation. The divergence time of the two clades is estimated to be 2-5 Mya (Huyse et al. 2004; Vanhove et al. 2012) and behaviors including sound may have diverged during this time, and hence show a phylogenetic signal (Malavasi et al. 2012). The two other sympatric 'sand goby group' species in shallow bays of Sweden (Kullander et al. 2012), Gobiusculus flavescens (Fabricius, 1779) and $P$. pictus, as well as the deep water species Pomatoschistus norvegicus (Collett, 1902), appear to belong to the same clade as P. minutus. P. marmoratus, the sister species to P. microps (Huyse et al. 2004; Vanhove et al. 2012), is not found in Sweden (Kullander et al. 2012). G. flavescens, which is semipelagic and not benthic, is at present not in the genus Pomatoschistus, rendering it paraphyletic and in need of revision (Vanhove et al. 2012).

The highly sympatric $P$. microps and P. minutus have similar habitat preferences with huge habitat overlaps (personal observation, Kullander et al. 2012) and are arguably the most similar species of the Swedish shallow water 'sand goby group' gobies. This suggests that courtship traits may show parallel evolution. However, the differences that do occur in habitat choice may explain courtship sounds and courtship repertoires. The three main differences that may affect courtship and hence result in divergence are nest substrate, bottom substrate and spawning depth. P. microps often build nests using empty shells of Cerastoderma cockles whereas $P$. minutus use larger shells e.g. from Mya clams (personal observation). Because the nest construction affects the sound (Lugli 2013), sound production could be adapted to the nest construction. The two species also prefer different bottom substrates, with $P$. microps being more prevalent in soft bottom areas whereas $P$. minutus is more common at sandy beaches (Nellbring 1986; Nellbring 1993; Magnhagen 1999). The preferred habitats can be only meters apart or be in completely different bays (personal observation). In addition, bottom substrate affects turbidity, and visibility has been shown to affect courtship and mate choice in fishes including P. minutus (Seehausen et al. 1997; Järvenpää and Lindström 2004; Engstrom-Öst and Candolin 2007; Michelangeli et al. 2015). Because P. microps prefer to spawn in even shallower water than P. minutus (less than one meter compared to a few meters, Nellbring 1986; Nellbring 1993), the range of light conditions differs as well as the distance from the shore. Hence, the visual and acoustic environment may correlate with spawning habitat. Furthermore, there are differences between $P$. minutus populations as well as between $P$. minutus and $P$. microps in the rhodopsin (RH1) genes, which are most likely involved in the spectral tuning mechanism (Larmuseau et al. 2009; Larmuseau et al. 2010), potentially causing diverging sensory biases (Ryan and Keddy-Hector 1992). These differences coincide with the general photic conditions (Larmuseau et al. 2009; Larmuseau et al. 2010). An alternative, but not mutually exclusive, mechanism for the divergence in courtship traits is character displacement (Pfennig and Pfennig 2009). Character displacement may decrease fitness loss due to reproductive interference (Gröning and Hochkirch 2008), and has been suggested as a potential mechanism for the divergence in courtship sound between $P$. minutus and P. pictus (Pedroso et al. 2013). Because mate choice takes time and prolonged conspicuous courtship increases exposure to predators (Magnhagen 1990; Magnhagen 1991), both males and females should be selected to avoid spending time on inspecting and courting the wrong species.

Changes in the environment due to human activities, such as aquatic noise and turbidity, have the potential to affect signal transmission, and are of increasing concern (Candolin and Wong 2012; Popper and Hawkins 2012; Chivers et al. 2013). Species with different acoustic courtship strategies may react differently to noise pollution. For example, $P$. minutus has a longer song repertoire with a lower volume than $P$. microps while also producing sound when the female is outside the nest (i.e. further away from the source of the sound). It has recently been shown that acoustic noise affect goby be havior (de Jong et al. 2016). Furthermore, increased levels of aquatic noise may increase reproductive interference. In gobies, it has been shown that behavior is affected by turbidity (Michelangeli et al. 2015) which can cause a mating system breakdown (Järvenpää and Lindström 2004). We show that P. minutus and 
P. microps differ in several acoustic and visual courtship traits, and hence females would still have enough available cues even in a perturbed environment.

To conclude, by comparing two species of Pomatoschistus, we highlight differences in courtship signals and behaviors such as train duration of courtship sounds and swimming speed during courtship. These differences may be consequential for how specific species react to a changing environment, including species identification and reproductive interference.

Acknowledgments M. Celander, K. de Jong and J. Wilson helped in the field and the Sven Lovén Centre of Marine Infrastructure in Kristineberg for use of their facilities, technical support and hospitality. We thank Calum Ninnes for valuable comments on the manuscript. The manuscript was greatly improved by the helpful comments from two anonymous reviewers. Financial support was provided by the Graduate School in Marine Environmental Research at the Gothenburg Centre for Marine Research, Helge Ax:son Johnssons stiftelse, Herbert \& Karin Jacobssons stiftelse, (to ELB), ASSEMBLE grant agreement no 227799 (to IM and $\mathrm{KH}$ ), Volkswagen foundation (to $\mathrm{KH}$ ), the Linnaeus Centre for Marine Evolutionary Biology at the University of Gothenburg which is supported by a Linnaeus-grant from the Swedish Research Councils VR and Formas (to OS).

\section{Compliance with ethical standards}

Ethics This study complies with the Swedish law and was performed under the ethical permits 135-2010 and 143-2012. All fish were released into their natural environment.

Open Access This article is distributed under the terms of the Creative Commons Attribution 4.0 International License (http:// creativecommons.org/licenses/by/4.0/), which permits unrestricted use, distribution, and reproduction in any medium, provided you give appropriate credit to the original author(s) and the source, provide a link to the Creative Commons license, and indicate if changes were made.

\section{References}

Amorim MCP, Neves ASM (2007) Acoustic signalling during courtship in the painted goby, Pomatoschistus pictus. J Mar Biol Assoc UK 87(4):1017-1023. doi:10.1017 /s0025315407056822

Bolgan M, Pedroso SS, Picciulin M, Fonseca PJ, Amorim MCP (2013) Differential investment in acoustic communication during social interactions in two closely-related sand goby species. Behaviour 150(2):133-152. doi:10.1163/1568539x00003041
Borg ÅA, Forsgren E, Magnhagen C (2002) Plastic sex-roles in the common goby - the effect of nest availability. Oikos 98(1):105-115

Bradbury JW, Vehrencamp SL (2011) Principles of animal communication, 2nd edn. Sinauer Associates, Inc., Sunderland

Candolin U, Wong BBM (eds) (2012) Behavioural responses to a changing world: mechanisms and consequences. Oxford University Press, Oxford

Chivers DP, Al-Batati F, Brown GE, Ferrari MCO (2013) The effect of turbidity on recognition and generalization of predators and non-predators in aquatic ecosystems. Ecol Evol 3(2):268-277. doi:10.1002/ece3.454

de Jong K, Amorim MCP, Fonseca PJ, Klein A, Heubel KU (2016) Noise affects acoustic courtship behavior similarly in two species of gobies. Proc Mtgs Acoust. 27: 010018. doi: $10.1121 / 2.0000272$

Engstrom-Öst J, Candolin U (2007) Human-induced water turbidity alters selection on sexual displays in sticklebacks. Behav Ecol 18(2):393-398. doi:10.1093/beheco/ar1097

Fonds M (1973) Sand gobies in the Dutch Wadden Sea (Pomatoschistus, Gobiidae, Pisces). Neth J Sea Res 6(4): 417-478. doi:10.1016/0077-7579(73)90001-x

Forsgren E (1997) Mate sampling in a population of sand gobies. Anim Behav 53:267-276

Forsgren E (1999) Sexual selection and sex roles in the sand goby. In: Almada VC, Oliveira RF, Gonçalves EJ (eds) Behaviour and conservation of littoral fishes. ISPA, Lisboa, pp 249-274

Forsgren E, Karlsson A, Kvarnemo C (1996) Female sand gobies gain direct benefits by choosing males with eggs in their nests. Behav Ecol Sociobiol 39(2):91-96

Giacomello E, Marri L, Marchini D, Mazzoldi C, Rasotto MB (2008) Sperm-duct gland secretion of the grass goby Zosterisessor ophiocephalus exhibits antimicrobial activity. J Fish Biol 73(7):1823-1828. doi:10.1111/j.10958649.2008.02069.x

Gröning J, Hochkirch A (2008) Reproductive interference between animal species. Q Rev Biol 83(3):257-282

Heubel KU, Schlupp I (2006) Turbidity affects association behaviour in male Poecilia latipinna. J Fish Biol 68(2):555-568. doi:10.1111/j.0022-1112.2006.00941.x

Heuschele J, Candolin U (2007) An increase in pH boosts olfactory communication in sticklebacks. Biol Lett 3(4):411-413. doi:10.1098/rsbl.2007.0141

Holt DE, Johnston CE (2015) Traffic noise masks acoustic signals of freshwater stream fish. Biol Conserv 187:27-33. doi:10.1016/j.biocon.2015.04.004

Huyse T, Van Houdt J, Volckaert FAM (2004) Paleoclimatic history and vicariant speciation in the "sand goby" group (Gobiidae, Teleostei). Mol Phylogenet Evol 32(1):324-336

Järvenpää M, Lindström K (2004) Water turbidity by algal blooms causes mating system breakdown in a shallow-water fish, the sand goby Pomatoschistus minutus. Proc R Soc B Biol Sci 271(1555):2361-2365

Jones JC, Reynolds JD (1999) Oxygen and the trade-off between egg ventilation and brood protection in the common goby. Behaviour 136:819-832

Kullander SO, Nyman L, Jilg K, Delling B (2012) Nationalnyckeln till Sveriges flora och fauna. Strålfeninga fiskar. Actinopterygii. Artdatabanken, SLU, Uppsala

Kvarnemo C (1994) Temperature differentially affects male and female reproductive rates in the sand goby: consequences for 
operational sex-ratio. Proc R Soc B Biol Sci 256(1346):151156

Kvarnemo C, Forsgren E, Magnhagen C (1995) Effects of sex ratio on intra- and inter-sexual behaviour in sand gobies. Anim Behav 50:1455-1461

Larmuseau MHD, Raeymaekers JAM, Ruddick KG, Van Houdt JKJ, Volckaert FAM (2009) To see in different seas: spatial variation in the rhodopsin gene of the sand goby (Pomatoschistus minutus). Mol Ecol 18(20):4227-4239. doi:10.1111/j.1365-294X.2009.04331.x

Larmuseau MHD, Huyse T, Vancampenhout K, Van Houdt JKJ, Volckaert FAM (2010) High molecular diversity in the rhodopsin gene in closely related goby fishes: a role for visual pigments in adaptive speciation? Mol Phylogenet Evol 55(2): 689-698. doi:10.1016/j.ympev.2009.10.007

Lehtonen TK, Kvarnemo C (2015a) Infections may select for filial cannibalism by impacting egg survival in interactions with water salinity and egg density. Oecologia 178(3):673-683. doi:10.1007/s00442-015-3246-1

Lehtonen TK, Kvarnemo C (2015b) Odour cues from suitors' nests determine mating success in a fish. Biol Lett 11(5): 20150021. doi:10.1098/rsbl.2015.0021

Lindström K, Lugli M (2000) A quantitative analysis of the courtship acoustic behaviour and sound patterning in male sand goby, Pomatoschistus minutus. Environ Biol Fish 58(4): 411-424

Locatello L, Mazzoldi C, Rasotto MB (2002) Ejaculate of sneaker males is pheromonally inconspicuous in the black goby, Gobius niger (Teleostei, Gobiidae). J Exp Zool 293(6):601-605

Lugli M (2013) Sand pile above the nest amplifies the sound emitted by the male sand goby. Environ Biol Fish 96(8): 1003-1012. doi:10.1007/s10641-012-0097-Z

Lugli M, Torricelli P (1999) Prespawning sound production in Mediterranean sand-gobies. J Fish Biol 54(3):691-694. doi:10.1006/jfbi.1998.0898

Magnhagen C (1990) Reproduction under predation risk in the sand goby, Pomatoschistus minutus, and the black goby, Gobius niger: the effect of age and longevity. Behav Ecol Sociobiol 26(5):331-335

Magnhagen C (1991) Predation risk as a cost of reproduction. Trends Ecol Evol 6(6):183-185

Magnhagen C (1998) Alternative reproductive tactics and courtship in the common goby. J Fish Biol 53(1):130-137

Magnhagen C (1999) Alternative mating tactics, nest defence and courtship in gobies - just a matter of size? In: Almada VC, Oliveira RF, Gonçalves EJ (eds) Behaviour and conservation of littoral fishes. ISPA, Lisboa, pp 275-300

Malavasi S, Gkenas C, Leonardos I, Torricelli P, McLennan DA (2012) The phylogeny of a reduced 'sand goby' group based on behavioural and life history characters. Zool J Linnean Soc 165(4):916-924. doi:10.1111/j.1096-3642.2012.00832.x

Michelangeli M, Tuomainen U, Candolin U, Wong BBM (2015) Habitat alteration influences male signalling effort in the Australian desert goby. Behav Ecol 26(4):1164-1169. doi:10.1093/beheco/arv060

Miller PJ (1975) Age-structure and life-span in the common goby. J Zool 177:425-448
Miller PJ (1986) Gobiidae. In: Whitehead PJP (ed) Fishes of the north-eastern Atlantic and the Mediterranean Vol 3. Unesco, Paris

Mück I (2016) The role of an environmental gradient in driving population divergence in common gobies (Pomatoschistus microps). Universität Tübingen

Nellbring S (1986) A quantitative and experimental stufy of goby (Pomatoschistus spp.) nests on a shallow soft bottom, northern Baltic proper. Ophelia 25(1):15-23

Nellbring S (1993) Spawning of two Pomatoschistus species (Gobiidae) in relation to nest availability and depth: a field experiment. Neth J Sea Res 31(2):173-179. doi:10.1016 /0077-7579(93)90007-f

Nyman K-J (1953) Observations on the behaviour of Gobius microps. Acta Soc pro Fauna et Flora Fenn 65:1-11

Pampoulie C, Lindström K, St Mary CM (2004) Have your cake and eat it too: male sand gobies show more parental care in the presence of female partners. Behav Ecol 15(2):199-204

Pedroso SS, Barber I, Svensson O, Fonseca PJ, Amorim MCP (2013) Courtship sounds advertise species identity and male quality in sympatric Pomatoschistus spp. gobies. PLoS One 8(6):e64620. doi:10.1371/journal.pone.0064620

Pfennig KS, Pfennig DW (2009) Character displacement: ecological and reproductive responses to a common evolutionary problem. Q Rev Biol 84(3):253-276

Popper AN, Hawkins A (eds) (2012) The effects of noise on aquatic life. Springer, New York

Radford AN, Kerridge E, Simpson SD (2014) Acoustic communication in a noisy world: can fish compete with anthropogenic noise? Behav Ecol 25(5):1022-1030. doi:10.1093 /beheco/aru029

Ryan MJ, Keddy-Hector A (1992) Directional patterns of female mate choice and the role of sensory biases. Am Nat 139:S4 S35

Seehausen O, vanAlphen JJM, Witte F (1997) Cichlid fish diversity threatened by eutrophication that curbs sexual selection. Science 277(5333): 1808-1811

Svensson O, Kvarnemo C (2005) The importance of sperm competition risk and nest appearance for male behavior and female choice in the sand goby, Pomatoschistus minutus. Behav Ecol 16:1042-1048. doi:10.1093/beheco/ari085

Svensson O, Magnhagen C, Forsgren E, Kvarnemo C (1998) Parental behaviour in relation to the occurrence of sneaking in the common goby. Anim Behav 56:175-179

Vallon M, Anthes N, Heubel KU (2016) Water mold infection but not paternity induces selective filial cannibalism in a goby. Ecol Evol. doi:10.1002/ece3.2403

Vanhove MPM et al (2012) Phylogenetics and biogeography of the Balkan sand gobies' (Teleostei: Gobiidae): vulnerable species in need of taxonomic revision. Biol J Linn Soc 105(1):73-91. doi:10.1111/j.1095-8312.2011.01781.x

Wilkins MR, Seddon N, Safran RJ (2013) Evolutionary divergence in acoustic signals: causes and consequences. Trends Ecol Evol 28(3):156-166. doi:10.1016/j.tree.2012.10.002 